\title{
The role of research methodology in the rational use of technology in monitoring and preventing communication disorders
}

\author{
BRASÍLIA M. CHIARI ${ }^{1}$ and BÁRBARA N.G. GOULART ${ }^{2}$ \\ ${ }^{1}$ Departamento de Otorrinolaringologia e Distúrbios da Comunicação Humana, Universidade Federal de São Paulo \\ Rua Botucatu, 802, 04023-062 São Paulo, SP, Brasil \\ ${ }^{2}$ Departamento de Otorrinolaringologia e Distúrbios da Comunicação Humana, Universidade Federal de São Paulo \\ Centro Universitário Feevale, Instituto de Ciências da Saúde, Feevale, Rodovia RS 239, 2755 \\ 93352-000 Novo Hamburgo, RS, Brasil \\ Manuscript received on July 3, 2008; accepted for publication on March 11, 2009; \\ presented by LUIZ R.TRAVASSOS
}

\begin{abstract}
Studies showing stronger scientific evidence related to speech, language and hearing pathology (SLP) have an impact on the prevention and rehabilitation of human communication and gained ground in SLP research agenda. In this paper we discuss some aspects and directions that should be considered for in-depth knowledge about speech, language and hearing needs in different population groups (age group, gender and other variables according to specific related disorders) for improved comprehensive care, successful efforts and effective use of financial and human resources. It is also discussed the decision making process for requesting complementary evaluations and tests, from routine to highly complex ones, that should be based on each test and/or procedure and their contribution to the diagnosis and therapeutic planning. In fact, it is crucial to have reliable parameters for planning, preventing and treating human communication and its related disorders. Epidemiology, biostatistics and social sciences can contribute with more specific information in human communication sciences and guide more specific studies on the international science and technology agenda, improving communication sciences involvement in the international health-related scientific scenario.
\end{abstract}

Key words: communication disorders, diagnosis of health situation, epidemiology, epidemiologic measurements, needs assessment, cost-effectiveness evaluation.

\section{INTRODUCTION}

Given the premise that human communication is an important instrument to share experiences involving human beings, there is a need to acquire further knowledge about speech, language and hearing biological processes and variables involved in communication disorders. Human Communication Sciences are a major knowledge field to be globally explored.

In recent decades, allied to huge technology advancements, biosciences have produced a lot of knowl-

In commemoration of the $75^{\text {th }}$ anniversary of Escola Paulista de Medicina/Universidade Federal de São Paulo. Correspondence to: Dr. Brasília Maria Chiari

E-mail: chiaribra@uol.com.br edge, mainly in the last few years. Along with that, the role of Speech, Language and Hearing Sciences (SLHS) has been recognized and research on human communication has been increasingly developed, contributing to much of the knowledge applied nowadays (Goulart and Chiari 2007a).

All knowledge, either common or based on magical, religious, philosophical, scientific or artistic interpretations of reality, originates from practical problems (Barata 1998).

Studies showing stronger scientific evidences of speech, language and hearing pathology (SLP) impact on the prevention and rehabilitation of human commu- 
nication have recently gained ground in SLP research agenda and have promoted the inclusion of SLP providers in health teams, contributing for a more comprehensive care approach in health promotion (Goulart and Chiari 2007a).

In this sense, it is extremely important to ascertain and broaden the arguments, knowledge and practices that have already been widely disseminated into other areas of knowledge to advance knowledge related to the evaluation, diagnosis and management of human communication and its related disorders (Goulart and Chiari 2007a).

The knowledge of the health-disease process in its collective sense only crossed the threshold of positivism in the $17^{\text {th }}$ century, when concepts of population, state and collectivity gained social significance (Barata 1998).

The epistemological threshold was crossed in the $19^{\text {th }}$ century with the application of statistics and rates, the development of causal theories and definition of research methods, and in the first half of the $20^{\text {th }}$ century with the transition of this discipline towards epidemiological science with the use of analytical instruments such as statistics, which defined the collective quality of an object and the systematization of methods (Barata 1998).

However, SLHS needs to further advance and researchers should bear in mind the need for stronger evidences about all technology involved in the evaluation, diagnosis and treatment of communication disorders.

In addition, there is a need for population surveys that could provide more detailed information on the characteristics of individuals who are susceptible to communication disorders. There should be consistent assessment methods and reproducibility of studies on human communication, communication disorders and a better understanding of their human variability worldwide.

In this paper we focus on some topics to discuss the rational use of technology to evaluate, treat or prevent communication disorders and its association to population surveys.

Population Surveys and SpeEch, Language AND HEARING SCIENCES

In-depth knowledge about speech, language and hearing needs in different population groups (age group, gender and other variables according to specific related disor- ders) is vital for more effective efforts and use of financial and human resources, as well as to support the development and improvement of actions for human communication health maintenance and promotion in collective health. It comes, whenever is possible, to develop collective health.

Also, there is scarce epidemiological data on the need for speech, language and hearing care. There is also a need to explore care needs based on local realities, and to conduct efficacy, cost-effectiveness studies and systematic reviews. These studies would require many researchers but with similar methodology to provide more powerful evidence (Goulart and Chiari 2007a). They could provide more consistent evidences for the advancement of speech, language and hearing actions, and the progress of sciences related to human communication (Goulart and Chiari 2007a).

It should be borne in mind that not all health disorders, even those involving human communication, are preventable, and input from users of speech, language and hearing services is neither sufficient nor appropriate scientific and methodological-based evidence for the decision making process about technologies and resources that should be available for speech, language and hearing care (Goulart and Chiari 2007a).

Besides, knowledge production should be spread, as much as possible, in scientific communication media, meetings and journals, as well as among speechlanguage pathologists, audiologists and undergraduate students by the inclusion of these subjects in undergraduate or graduate studies, as already seen in other scientific areas (Goulart and Chiari 2007a).

Evidence about health-related technology used in uncommon circumstances when its efficacy and accuracy are not well established - and may be different from that evidenced in previous studies - and other applications of technology either not fully investigated or established should be taken into consideration in the decision making process on diagnosis and treatment approach in human communication and related disorders (Assmann et al. 2000, Goulart and Chiari 2007a). New technologies exercise special fascination; they are not always better, but almost always more expensive than common complementary or similar options available (Goulart and Chiari 2007a). 
Speech-language therapists and audiologists have to be aware of these issues and look for input that can provide stronger evidence to their decision making about the application of tools and instruments in their practice (Goulart and Chiari 2007a).

Population-based research can provide input for the analysis and comparison of other factors that, for example, can potentially affect the association between school performance and verbal communication disorders in children (Goulart and Chiari 2007b).

Few studies have investigated factors associated to communication disorders in a college-age African American students taking into consideration that individuals in this group may be the most amenable to participate in research studies because of their age and education. These are the same individuals who will be recruited for future research trials in the United States (Diaz et al. 2008). This study is illustrative as it aimed at identifying variables that could affect their participation in studies with the purpose of developing and improving recruitment strategies for involving African Americans in future clinical research projects. These projects are based on a sample that would actually be representative of the population diversity in the United States (Diaz et al. 2008).

It is necessary to have a better understanding of the factors affecting the decision to participate in research studies (Diaz et al. 2008). Attention to sensitivity of information collected and collaboration with researchers who have background knowledge on the studied population may improve the participation of all population strata in population-based surveys.

In summary, the use of more consistent terminology to describe communication disorders would be valuable to improve diagnostic accuracy and would allow comparisons between data from different regions and population groups around the world (Goulart and Chiari 2007b).

Language acquisition and development in boys and girls seem different especially because they have different upbringings and interactions with their environment (Goulart and Chiari 2007b). These findings support theories of multicausality proposed in many epidemiological studies showing health conditions being strongly related to the environment (Goulart and Chiari 2007b).
There have been major efforts to improve the application of statistical methods in medical research, although there remain inaccuracies and misconceptions (Assmann et al. 2000, Alexander 2007). It is common to use statistical hypothesis tests to compare baseline variables among the study arms and apply the results to assess how "successful" randomization was (Alexander 2007). For example, a study where each of one of 28 baseline variables was tested three times and every intervention (three different types) was compared to the related placebo. Of 84 hypothesis tests performed, $8 p$ values were less than 5\% (Assmann et al. 2000, Alexander 2007). The authors claim this finding was "low and no greater than what would be expected by chance". They concluded that randomization was successful as evidenced by similar distributions of baseline demographic, health, and behavioral variables across treatment groups (Alexander 2007).

However, the application of hypothesis tests to measure the success of randomization is illogical, and may divert attention from a real problem (Alexander 2007). The null hypothesis, in this case, is that the observed between-arm difference in the baseline variable was due to chance. However, because the trial was randomized, we know that a difference in a baseline variable is due to chance (Alderson 2004, Alexander 2007). In other words, randomization ensures that the null hypothesis is true. The only reason for applying a hypothesis test for a between-arm comparison of a baseline variable is in the event that randomization is questioned and the investigators should not have any reasons for that (Alexander 2007).

Some authors apply hypothesis testing to identify variables that should be adjusted for in the analysis (Alderson 2004, Alexander 2007). For example, hypothesis tests are not a suitable approach to decide which variables should be adjusted for (Alexander 2007). This does not mean that baseline values should not be reported, but only that these hypothesis tests are "philosophically unsound, of no practical value and potentially misleading". The significance of baseline imbalance should be assessed according to the magnitude of difference and degree of association between the variable and the outcome (Alexander 2007). Baseline imbalance is unlikely to be a problem except in small trials (Alexander 2007). How- 
ever, when there are variables considered to be strong predictors of the outcome, they can be adjusted for, and this should be specified in advance in the analysis plan (Alexander 2007). It is essential to bear in mind that, if a study fails to find a statistically significant effect $(\mathrm{p}>0.05)$, it is tempting to conclude that the intervention does not work (Alderson 2000, Alexander 2007). However, this is not necessarily true. A result that is not statistically significant is, per se, an absence of evidence, and it does not mean an evidence of absence (Altman and Bland 1995). As mentioned before, we should think not only about the $p$-value, but also consider the magnitude of effect. For example, a study with a very small sample size would be able to detect only a very large effect (Alexander 2007). In other words, a $p$-value greater than 0.05 may be due to an inadequate sample size rather than to a small effect. The easiest way to think about the effect size is based on confidence intervals (usually $95 \%$ confidence intervals). The conclusions of a particular study should be drawn not only on the $p$-value, but also on whether confidence intervals include clinically important effect sizes. We can say that a reduction of HIV incidence by $40 \%$ would be clinically important. Thus, based on its confidence interval, we can neither confirm nor exclude an important effect (Alexander 2007, Goulart and Chiari 2007b).

In biomedical research, failure to account for regression to the mean can lead to several problems (Morton and Torgerson 2003, Bland and Altman 1994). For example, when planning studies, it is common to focus on populations whose rates of a given condition are high. If the condition varies over time, then it is likely that an extremely high level will be followed by a level which is not quite as high. This may mean that power calculations were optimistic. Another example is changing from baseline when patients are selected for a study based on extreme values of a variable and then that variable is likely to show regression to the mean compared to baseline (Morton and Torgerson 2003). This may be misleading and make researchers conclude that a benefit is due to the intervention provided to the patient (Morton and Torgerson 2003).

The lack of African Americans in research trials is often attributed to investigators' difficulties in recruiting and retaining minority subjects (Diaz et al. 2008). Stud- ies demonstrate African Americans being more difficult to recruit and having a variety of barriers to participation and retainment in research trials. This highlights the need to develop culturally appropriate, effective recruitment strategies. Such strategies may need to address factors such as a lack of minority investigators and mistrust, which are well-established barriers to participation (Diaz et al. 2008). Other factors, such as socioeconomic status, ease of participation, physician encouragement and the intervention under study may also affect study participation (Diaz et al. 2008). One should bear in mind all these considerations while planning and conducting studies that could provide more detailed data about the objects of study.

\section{CONSIDERING THE NeEd OF Instrument VALIDATION}

Decisions about requesting complementary evaluations and other tests, from routine to highly complex ones, should be based on each test and/or procedure and their contribution to the diagnosis and therapeutic planning (Goulart and Chiari 2007a).

Nowadays, we have a lot of instruments available in Brazil for screening and/or diagnosis of most communication disorders (Goulart and Chiari 2007a). However, all these instruments need to be validated in subjects with and without the disorder to be diagnosed for a more accurate evaluation of the instrument capability (Goulart and Chiari 2007a).

The translation of diagnosis and/or screening tests and/or approaches can be characterized by the measurement of their sensitivity, specificity and predictive values (Goulart and Chiari 2007a). It is important to take into account the population sample while validating instruments related to human communication, and there should be consider regional characteristics in speech and language evaluation, age group and occupation or professional activity in voice or orofacial motricity assessment, among others. Therefore, a comprehensive description of the studied population and diagnostic criteria applied in instrument validation study are key to the providers who will use the instrument or test in the clinical setting or in another research. Adequate instrument validation and knowledge of its technical properties in different population groups also can provide more input for decision makers to establish priorities and develop health 
program contents at different levels of management (Goulart and Chiari 2007a).

For further advances in this area, research centers and universities should continue to strongly contribute to the validation and improvement of knowledge about the application of the available technologies in human communication (Goulart and Chiari 2007a).

Taking as an example a study that examined the agreement between patient's self-reported depression symptoms and physician's documentation of these symptoms, there can be an indicator of how well selfreported symptoms predicted the medical diagnosis of depression in primary care patients (Ani et al. 2008). Two-thirds of depression patients were undiagnosed in primary care settings, and the agreement between a structured assessment and physician elicited or documented symptoms during a clinical encounter was very low (Ani et al. 2008). Authors call attention to the fact that interventions that include routine structured screening of primary care patients might also improve the rate of symptom identification.

The US National Institutes of Health requires the inclusion of underrepresented minorities in biomedical research. Despite this requirement, there is still a lack of African American representation in research trials (Diaz et al. 2008). For instance, studies have shown that African American participants comprise only $6 \%$ of cancer clinical trials and low African American participation is also seen in other types of studies (Diaz et al. 2008). This lack of participation limits the ability of researchers to generalize data from clinical trials to African Americans and may ultimately reinforce health inequalities in this population (Diaz et al. 2008).

\section{Rational Use of Health-Related Technologies:}

\section{RATIONALIZING COST-EFFECTIVENESS}

As some authors have described, incipient knowledge on the cost-effectiveness of health technology application has been quite evident and expressed in financial policies and procedure coverage, either in public health or in supplementary health, for example, health insurance (Krauss-Silva 2003). For further development of speech, language and hearing therapy in health-related services, it is necessary that increasingly more health providers have the appropriate knowledge and be able to use the available tools for evidence-based actions (Goulart and Chiari 2007a).

\section{FINAL CONSIDERATIONS}

Articles as the present one, and other education resources, cannot by themselves improve, up to an acceptable level, the quality of statistics in biomedical journals, and factors which are core to biomedical research process should be considered (Alexander 2007, Goulart and Chiari 2007b).

Some of these problems could be alleviated by making closer links between the training in biological and statistical disciplines (Alexander 2007). Statistical education of students in health-related sciences is sometimes poor, with the ambivalent attitude of students to numerical information often being worsened by an overly mathematical way of teaching (Alexander 2007). In recent years, efforts have been made to improve it, and we believe that they should draw on experience acquired in biostatistician training programs (Alexander 2007).

This should also be part of continuing education, although there are arguments against it (Pocock 1995).

We should try to ensure that choosing a valid statistical method is not a mystery, but a task that can be done comfortably, though sometimes being time-consuming: less like writing a grant application budget, and more like deciding what to have for dinner (Alexander 2007).

In fact, it is vital to have reliable parameters to planning, preventing and treating human communication and its related disorders. Epidemiology, biostatistics and social sciences can contribute in different ways to provide more specific information in human communication sciences.

\section{RESUMO}

Estudos que demonstram mais evidências científicas associadas ao impacto da Fonoaudiologia na prevenção e reabilitação da comunicação humana vêm ganhando maior espaço na agenda fonoaudiológica. Neste artigo discutimos alguns aspectos relacionados a essa questão, bem como direcionamentos a serem considerados para que conhecimento mais detalhado relacionado à Fonoaudiologia em estratos diferentes da população (como faixa etária, sexo, etc. associadas a estes agravos) esteja disponível, a fim de contribuir com a integralidade e efetividade dos recursos humanos e financeiros na atenção à saúde. Além 
disso, discutimos aspectos inerentes à solicitação de avaliações e exames complementares, os quais variam de baixa a alta complexidade, sendo necessário considerar, entre outros, a característica de cada um destes e sua contribuição no diagnóstico e/ou no planejamento terapêutico fonoaudiológico. É fundamental que contemos com parâmetros confiáveis para o planejamento terapêutico e tratamento dos distúrbios da comunicação humana, bem como fatores associados a estes. A epidemiologia, a bioestatística e as ciências sociais podem contribuir sob diferentes formas para que contemos com dados fonoaudiológicos mais específicos, além de direcionamentos para que os estudos fonoaudiológicos estejam mais diretamente vinculados à Política de Ciência e Tecnologia vigente e ampliem seu espaço no cenário científico internacional.

Palavras-chave: transtornos da comunicação, diagnóstico de situação de saúde, epidemiologia, medidas epidemiológicas, determinação das necessidades de cuidados em saúde, avaliação de custo-efetividade.

\section{REFERENCES}

AldERSON P. 2004. Absence of Evidence is not Evidence of Absence. Br Med J 328: 476-477.

AleXander N. 2007. What Not to Do in Medical Statistics. Rev Bras Saude Mater Infant 7: 327-338.

Altman DG AND Bland JM. 1995. Absence of evidence is not evidence of absence. Br Med J 311: 485.

Ani C, Bazargan M, Hindman D, Bell D, Faroog MA, Akhanjee L, Yemofio F, Baker R And RoDRIGUEZ M. 2008. Depression Symptomatology and Diagnosis: discordance between patients and physicians in primary care settings. BMC Fam Pract 9: 1.
Assmann SF, Pocock SJ, Enos LE and Kasten LE. 2000. Subgroup Analysis and Other (Mis)uses of Baseline Data in Clinical Trials. Lancet 355: 1064-1069.

BARATA RB. 1998. Epidemiologia e Saber Científico. Rev Bras Epidemiol 1: 14-27.

Bland JM and Altman DG. 1994. Some Examples of Regression Towards the Mean. Br Med J 309: 780.

Diaz VA, Mainous AGiII, McCall AA and Geesey ME. 2008. Factors Affecting Research Participation in African American College Students. Fam Med 40: $46-51$.

Goulart BNG AND ChIARI BM. 2007a. Screening versus Diagnostic Tests: an update in the speech, language and hearing pathology practice. Pró-Fono Rev Atual Cient 19: 223-232.

Goulart BNG AND CHIARI BM. 2007b. Prevalence of Speech Disorders in Schoolchildren and its Associated Factors. Rev Saúde Pública 41: 726-731.

Krauss-Silva L. 2003. Avaliação Tecnológica e Análise Custo-Efetividade em Saúde: a incorporação de tecnologias e a produção de diretrizes clínicas para o SUS. Ciência \& SC 8: 501-520.

Morton V And TORGERson DJ. 2003. Effect of Regression to the Mean on Decision Making in Health Care. Br Med J 326: 1083-1084.

Pocock SJ. 1995. Life as an Academic Medical Statistician and How to Survive it. Stat Med 14: 209-222. 